\title{
Kidney Transplantation in the Elderly
}

\author{
Edmund Huang, MD*, Dorry L. Segev, MD ${ }^{\dagger}$, and Hamid Rabb, MD* \\ *Department of Medicine, Johns Hopkins University, Baltimore, MD \\ †Department of Surgery, Johns Hopkins University, Baltimore, MD
}

\section{Summary}

There is an increase in the older incident end-stage renal disease population that is associated with an increasing prevalence of end-stage renal disease in the United States. This trend is paralleled by an increasing rate of kidney transplantation in the elderly. Although patient survival is lower in older versus younger kidney recipients, the elderly benefit from a reduction in mortality rate and improved quality of life with transplantation compared with dialysis. Immunologic, physiologic, and psychosocial factors influence transplant outcomes and should be recognized in the care of the elderly transplant patient. In this review, we discuss transplantation in the elderly patient, particularly the topics of access to transplantation, patient and graft survival, the impact of donor quality on transplant outcomes, immunology and immunosuppression of aging, and ethical considerations in the development of an equitable organ allocation scheme.

\section{Keywords}

Elderly; kidney transplant; aging; patient survival; graft survival

It generally is accepted that patients who receive a successful kidney transplant gain a survival benefit compared with remaining on dialysis. Wolfe et al, ${ }^{1}$ using data from the United States Renal Data System (USRDS) of more than 250,000 incident dialysis patients from 1991 to 1996, reported that the survival of patients receiving a deceased donor kidney transplant was longer than that of patients maintained on dialysis while awaiting transplantation. Although the survival advantage of transplantation was most pronounced in younger end-stage renal disease (ESRD) patients, patients of all ages gained additional years of life with transplant compared with dialysis. ${ }^{1}$ Therefore, because of this mortality benefit, kidney transplantation is the treatment modality of choice for ESRD.

According to USRDS data, the prevalence of ESRD in the United States is increasing disproportionately to its incidence, likely because patients are living longer with ESRD (see the article by Eggers in this issue). USRDS data also indicate that the incident ESRD population is aging. In 1990, there were 21,479 incident ESRD patients aged 65 or older in the United States; this number steadily increased to 53,842 by 2006 (see the article by Eggers in this issue). There was a slower increase in kidney transplantation in patients older than age 65 during the same time period, such that by 2006, patients older than age 65 accounted for $13.3 \%$ of all kidney transplant recipients. ${ }^{2}$ Nevertheless, only a limited number of elderly ESRD patients

Address reprint requests to Hamid Rabb, MD, Department of Medicine, Ross 965, Johns Hopkins Hospital, 720 Rutland Ave, Baltimore, MD 21205.hrabb1@jhmi.edu.

Publisher's Disclaimer: This is a PDF file of an unedited manuscript that has been accepted for publication. As a service to our customers we are providing this early version of the manuscript. The manuscript will undergo copyediting, typesetting, and review of the resulting proof before it is published in its final citable form. Please note that during the production process errors may be discovered which could affect the content, and all legal disclaimers that apply to the journal pertain. 
are considered for transplantation. Although reasons for this are unclear, it is possible that stringent selection criteria, a perception among health care providers of limited utility of kidney transplantation in the elderly, and decreased interest in kidney transplantation among older patients may be contributing factors. In 2006, less than 6\% of ESRD patients older than age 65 were placed on the deceased-donor waiting list. ${ }^{2}$ Access to transplantation, defined by registration for the deceased-donor waiting list or receiving a live-donor renal transplant, decreases with advancing age and is particularly low for elderly women. There is a $30 \%$ decrease in access to transplantation for each decade increase in age; when compared with comorbidity-matched male counterparts, access to transplantation was $29 \%$ lower for women aged 65 to 75 and $59 \%$ lower for women older than age $75 .^{3}$

Several factors need to be considered when evaluating an elderly recipient for transplantation. In addition to recipient comorbidities, donor quality, immunosuppression, dialysis vintage, and the strength of social support networks affect the success of transplantation. Furthermore, the impact of transplantation on quality of life and mortality is not equivalent in the older versus the younger patient. ${ }^{1,4}$ Given the persistent shortage of donor organs and the advancing age of the ESRD population, the ethical balance of utility (allocation of organs to those who derive the greatest benefit) versus justice (equal access to transplantation for all age groups) is a significant dilemma in the development of equitable organ allocation schemes. In this review, we discuss factors central to transplantation of the elderly recipient, including patient and graft survival, the impact of donor quality on transplant outcomes, immunology, and immunosuppression of the aging patient, and ethical considerations in organ allocation.

\section{Patient and Allograft Outcomes in the Elderly}

\section{Patient Survival}

Numerous studies have indicated that there is less mortality in patients who receive a kidney transplant compared with those who remain on dialysis. Wolfe et al ${ }^{1}$ compared mortality rates of deceased donor kidney transplant recipients with a comparable population of wait-listed dialysis patients. When the study was published in 1999, only about $1 \%$ of ESRD patients older than age 70 received a deceased donor renal transplant in the United States. Therefore, patients older than age 70 were excluded from the analysis. In an analysis of patient survival from the time of initial placement on the transplant waiting list, the relative risk of death 18 months after kidney transplant was lower in all age groups compared with the reference group of wait-listed dialysis patients. ${ }^{1}$ However, when projected life years were compared between transplantation and dialysis, a greater mortality benefit was estimated for younger transplant recipients than older recipients ( 17 additional years of life with transplant for patients aged 20-39, and 11 years for patients aged 40-59 compared with 4 years for patients older than age 60). ${ }^{1}$

Taking into account a recent increase in transplantation rates in older patients, a similarly designed study was conducted in 2007 by Rao et $\mathrm{al}^{5}$ using data reported by US transplant centers on patients older than age 70 to the Organ Procurement and Transplantation Network (OPTN)/Scientific Registry of Renal Transplant Recipients. Transplant recipients older than age 70 had a lower risk for mortality compared with wait-listed dialysis patients (age 70-74 y: RR, 0.59 ; 95\% CI, 0.53-0.65; age $\geq 75$ : RR, 0.58 ; 95\% CI, 0.52-0.65). ${ }^{5}$ Furthermore, a survival benefit also was seen in elderly recipients of an expanded criteria donor (ECD) kidney (RR mortality of ECD versus wait-list: $0.75 ; 95 \%$ CI, 0.65-0.86), ${ }^{5}$ defined as one from a donor age 60 or older or a donor aged 50 to 59 with two of the following: hypertension, death from stroke, or terminal creatinine level greater than 1.5. 5,6

A smaller study by Oniscu et $\mathrm{al}^{7}$ compared mortality between renal transplant recipients and wait-listed dialysis patients older than the age of 60 in Scotland. Although there was a higher risk of death in the first 30 days compared with dialysis (RR, 4.91; 95\% CI, 2.09-11.52), 
transplantation was associated with a lower risk of death thereafter (31-365 days posttransplant: RR, 0.71 ; 95\% CI, 0.35-1.41; and > 365 days posttransplant: RR, 0.35; 95\% CI, 0.22-0.54). ${ }^{7}$

The estimated life expectancy was approximately 4 years greater with a kidney transplant than remaining on dialysis. ${ }^{7}$ Furthermore, an Australian study also reported a survival benefit in renal transplant recipients older than the age of 60 compared with dialysis. ${ }^{8}$

\section{Relative Benefit of Transplantation: Older Versus Younger Recipients}

Even though there is evidence of a survival benefit for the elderly who receive a kidney transplant compared with staying on dialysis, numerous studies have suggested that the survival benefit is less for the elderly compared with younger transplant recipients, ${ }^{1,4,9-13}$ and a decrease in allograft survival among elderly transplant recipients has been reported consistently. ${ }^{14-16}$ Taking into account an expected increased mortality in the elderly population, both graft survival and death-censored graft survival (ie, graft survival excluding death with a functioning graft) are equally important measures of allograft outcome in elderly transplant recipients. Meier-Kriesche et al, ${ }^{15}$ using kidney transplant data submitted to the United States Renal Transplant Scientific Registry between 1988 and 1997, reported that both graft survival and death-censored graft survival were significantly lower in kidney transplant recipients older than age 65 compared with younger age groups. However, a later study using OPTN data incorporated a longer period of follow-up evaluation on kidney recipients from a later era (1995-2000) and found that although graft survival worsened as recipient age increased, death-censored graft survival improved with advancing age. ${ }^{16}$ Analogous data from other studies examining graft outcomes in transplant recipients from more recent years support that there is little difference in death-censored graft survival in older recipients compared with younger recipients. ${ }^{14,17-19}$

The causes of graft loss differ depending on the age of the recipient. Observational studies have noted a decreasing rate of acute rejection with advancing age. ${ }^{17,20}$ Nevertheless, the impact of acute rejection on graft loss may be more pronounced in the elderly. Meier-Kriesche et al ${ }^{21}$ reported that the 5-year death-censored graft survival adjusted for donor and recipient characteristics in patients who experienced an episode of acute rejection within the first 6 transplant months was $82.1 \%$ in patients aged 18 to 35 compared with $59.9 \%$ in patients older than age 65 . Although graft loss owing to an immunologic cause is more common in the younger transplant population, death with a functioning graft is the most common cause of graft loss in the elderly. ${ }^{14,22}$ Compared with transplant recipients between the ages of 18 to 29 , patients older than age 65 are seven times more likely to die with a functioning graft. ${ }^{23}$

\section{Effect of Donor Characteristics on Transplant Outcomes}

Because elderly recipients are more likely to die with a functioning graft, some have argued that older or marginal kidneys should be allocated preferentially to older recipients. In the United States, the United Network for Organ Sharing allocation scheme does not take into account age-matching of donor and recipient and the decision to waitlist a patient for an ECD kidney is left to the discretion of the transplant center. In 2006, 34.3\% of ECD kidneys were given to patients older than age 65 in the United States. ${ }^{24}$ However, to what extent does donor quality affect graft survival and/or mortality in the elderly population?

\section{Effect of Waiting Time}

ECD kidneys may be an attractive option for elderly transplant candidates because they can reduce the waiting period for a transplant. The detrimental effect of prolonged waiting time on allograft outcomes was illustrated in a comparative analysis of kidney transplant survival with paired donor kidneys given to patients on dialysis for longer than 2 years compared with those on dialysis for less than 6 months. ${ }^{25}$ Patients who received dialysis for a longer duration of 
time before the transplant had lower 5- and 10-year graft survival rates. ${ }^{25}$ Additional studies have indicated that the survival benefit with transplantation is greatest in recipients who have the shortest waiting time. ${ }^{26,27}$ However, by definition, ECD kidneys are associated with a higher risk of graft loss compared with standard criteria donor (SCD) kidneys. Allograft and patient survival for individuals older than age 60 are worse for recipients of ECD kidneys compared with those of living donor and SCD kidneys, even after adjusting for duration of pretransplant dialysis and other donor and recipient factors. ${ }^{22}$ Furthermore, individuals older than age 60 who received an ECD kidney had worse renal function at 1 year compared with recipients of a living donor or SCD kidney. ${ }^{22}$

\section{The European Experience}

Eurotransplant Seniors Program initiative-In an initiative to reduce waiting time for elderly recipients, the Eurotransplant Seniors Program (ESP) was developed to match the life expectancy of organs and recipients by allocating older deceased donor kidneys to elderly recipients. ESP became fully implemented into the Eurotransplant Kidney Allocation System in January 2001. The ESP algorithm allocates kidneys from donors older than age 65 to recipients older than age 65 within a local or narrow geographic area to minimize cold ischemia time. Organs are allocated by blood group and waiting time only. Candidates older than age 65 may be eligible to receive organs from donors younger than age 65 if they do not consent for ESP. These younger organs continue to be allocated under the Eurotransplant Kidney Allocation System, which allocates according to the degree of HLA mismatch, waiting time, expected cold ischemia time, and the balance of donors and recipients between countries in the Eurotransplant region.

ESP outcomes-The 5-year outcomes of recipients transplanted under ESP were reported recently in 2008. ${ }^{12}$ In the ESP era, the median waiting time increased for younger recipients, perhaps because of an increasing number of patients on the transplant waiting list, whereas waiting time decreased for recipients older than age $65 .{ }^{12}$ However, 5 -year patient and graft survival rates were worse for those older than age 65 who received an older kidney under ESP (60\% and $47 \%$, respectively) compared with those for recipients aged 60 to 64 who received a kidney under the Eurotransplant Kidney Allocation System (74\% and 64\%, respectively).

12 Thus, the ESP experience indicates that elderly transplant patients fare better by receiving a transplant from a younger donor. However, the mortality rate of patients transplanted under ESP has not been compared with that of wait-listed dialysis patients, and therefore the relative benefit of earlier transplantation under the ESP algorithm compared with waiting for a younger deceased donor kidney is not known.

\section{Effect of ECD Transplantation on Life Expectancy}

It is important to characterize which patients would benefit from accepting a marginal kidney in exchange for earlier transplantation. To address this question, Schold and Meier-

Kriesche $^{28}$ used data from the Scientific Registry of Renal Transplant Recipients database to project life expectancy for wait-listed candidates and living donor, SCD, and ECD transplant recipients in the United States. The life expectancy for ECD recipients older than age 65 who received earlier transplantation (defined as $<2$ years of dialysis; $5.6 \mathrm{y}$; 95\% CI, 5.1-6.5) was similar to that for later transplantation ( $>4$ years of dialysis) with a living donor $(5.5 \mathrm{y} ; 95 \%$ CI, 4.7-6.5) or SCD kidney (5.3 y; 95\% CI, 4.8-6.0). ${ }^{28}$ Patients with a primary diagnosis of diabetes in all age groups had a similar life expectancy with earlier ECD transplantation compared with later SCD transplantation. ${ }^{28}$ It is important to note that perioperative factors including the risks of the surgical procedure, anesthesia, delayed graft function, and heightened immunosuppression contribute to an increased risk for mortality early after transplantation compared with dialysis. However, the long-term risk (>226 days posttransplant) for mortality with transplant is lower than that of dialysis. ${ }^{27}$ In regions of the United States with long median 
waiting times ( $>1,350$ days), subgroups associated with a survival benefit from ECD transplantation include recipients older than age 40, both sexes, all races, non-Hispanic ethnicity, unsensitized patients, and diabetes and hypertension as a cause of ESRD. ${ }^{27}$ In contrast, in regions with a shorter median waiting time ( $<1,350$ days), only recipients with diabetes as a cause of ESRD had a survival benefit with ECD transplantation. ${ }^{27}$

\section{Summary and Conclusions}

It can be inferred from these data that ECD transplantation should be offered to all elderly candidates without a living donor who otherwise would have a prolonged wait for a SCD kidney and all elderly diabetic candidates regardless of anticipated waiting time. In contrast, we have found in our clinical experience that elderly patients who receive a kidney that does not work well frequently have increased morbidity and mortality than younger recipients of poorly functioning grafts.

\section{Influence of Recipient Age on Mortality}

\section{Effect of Comorbid Conditions}

Elderly recipients are more likely to have comorbid conditions at the time of transplant than younger patients. These conditions are associated with higher posttransplant mortality. An observational study of the OPTN/United Network for Organ Sharing database examined the influence of recipient comorbidities, including a history of angina/coronary artery disease, peripheral vascular disease, cerebrovascular disease, malignancy, chronic obstructive pulmonary disease, and diabetes on short-term mortality (within 90 and 365 days after transplant) in older patients. ${ }^{29}$ Older patients were more likely to have comorbid conditions at the time of transplant than their younger counterparts (48.2\% of recipients older than age 60 had no comorbidities compared with $28.9 \%$ of patients younger than age 60$).{ }^{29}$ In patients older than age 60, a history of angina/coronary artery disease, chronic obstructive pulmonary disease, or diabetes increased the odds of 1-year mortality anywhere from $30 \%$ to $121 \%$ compared with recipients older than age 60 with no comorbidities. ${ }^{29}$ When patients older than age 60 received an ECD kidney or experienced delayed graft function, the presence of any of the earlier-described 6 comorbidities increased the odds of mortality in the first year on the order of $59 \%$ to $351 \% .^{29}$

\section{Cardiovascular Disease}

The risk of cardiovascular disease increases with the progression of kidney disease ${ }^{30}$ and cardiovascular disease accounts for $38 \%$ of all deaths in the ESRD population. ${ }^{2}$ Side effects of commonly used immunosuppressive medications include weight gain, diabetes, hypercholesterolemia, and hypertension, all of which may contribute significantly to cardiovascular risk. Similar to the dialysis population, the most common cause of death in kidney transplant patients is cardiovascular disease. ${ }^{23}$ Although there is a linear increase in cardiovascular mortality with age in both wait-listed patients awaiting a transplant and transplant recipients, the rate of increase in cardiovascular mortality with age in wait-listed patients exceeds that of transplant recipients (Fig. 1A). ${ }^{31}$ Furthermore, the risk of cardiovascular death for all age groups is greater for wait-listed patients than for transplant patients (Fig. 1A). ${ }^{31}$ Thus, it can be inferred that transplantation is associated with a decreased risk of cardiovascular death compared with dialysis. In addition, although advancing age increases the risk for cardiovascular death in ESRD patients, transplantation attenuates the effect of age on cardiovascular mortality. 


\section{Infectious Disease}

Infection-related mortality is the second most common cause of death in the ESRD and transplant populations. ${ }^{2}$ In general, older patients are more susceptible to infectious death than younger patients, ${ }^{20}$ however, age has a greater impact on infection-related mortality in transplant patients compared with its effect in their dialysis counterparts. In a study of causespecific mortality rates in the ESRD population, transplanted patients had an exponential increase in the risk of infectious death by age, whereas only a linear association between infectious death and age was observed in wait-listed patients (Fig. 1B) ${ }^{31}$ Another study reported that infectious death represents the most common cause of first-year mortality in transplant patients older than age 60 , a period during which the relative degree of immunosuppression is the highest (Fig. 2). ${ }^{29}$ These data show that the elderly are more vulnerable to the effects of immunosuppression, perhaps because of age-related immunosenescence. Nevertheless, despite the increased effect of age on infectious death with transplantation, transplantation is associated with a lower risk of infection-related mortality in all age groups compared with dialysis. ${ }^{31}$

\section{Summary and Conclusions}

Thus, although older transplant patients have a higher risk for mortality than their younger counterparts, elderly transplant patients have a lower risk of all-cause mortality and death caused by cardiovascular disease and infections than dialysis.

\section{The Immunology of Aging \\ Introduction}

It generally is assumed that aging is associated with a progressive decline in immune function. However, the aging phenotype is heterogeneous and immune constitution is variable in healthy older adults compared with elderly transplant recipients with comorbidities. Some of the changes in immunity occur in all adults as a natural byproduct of aging; others are greatly affected by co-existing illness. As a consequence, some elderly transplant recipients may be more susceptible to overimmunosuppression whereas others may have a greater tendency to reject.

Table 1 summarizes the changes that occur with immunosenescence. The immune system consists of innate immunity, comprised mainly of monocytes, natural killer cells, and dendritic cells, and adaptive immunity, involving $\mathrm{T}$ and $\mathrm{B}$ lymphocytes. Immunosenescence affects both branches; however, aging has a greater effect on adaptive immunity. These changes result in part from thymic involution, replicative senescence, and atrophy of secondary lymphoid organs, leading to a decrement in circulating lymphocytes and altered cytokine profiles.

\section{Hematopoiesis and Stem Cells}

There is evidence that hematopoiesis is impaired with aging. The stem cell compartment is believed to consist of distinct categories of lineage-biased hematopoietic stem cells (HSCs). 32 These categories consist of lymphoid-biased HSCs, which primarily differentiate into lymphoid cells, myeloid-biased HSCs, which preferentially differentiate into myeloid cells, and balanced HSCs, which give rise to about $10 \%$ myeloid and $90 \%$ lymphoid cells. ${ }^{33}$ Myeloidbased HSCs have a blunted response to the lymphopoietin, interleukin-7, resulting in a limited capacity to generate T- and B-lymphocyte precursors. ${ }^{34}$ Furthermore, myeloid-based donor HSCs are slow to repopulate after transplantation into irradiated mice ${ }^{34}$ whereas lymphoidbiased HSCs respond more quickly to hematopoietic stress. ${ }^{33}$ Clonal studies in a murine model suggest that a shift in the stem cell compartment from predominantly lymphoid-biased to myeloid-biased HSCs occurs with aging, ${ }^{35}$ and this may help to explain the attenuated hematopoietic response of the aged individual. 


\section{Adaptive Immunity}

The critical steps of thymocyte development occur in the thymus, including somatic rearrangement of the T-cell receptor (TCR) genes, which accounts for the diversity of TCR specificities on naive T cells. A broad repertoire of TCR specificities is crucial for immune activation to a diverse set of foreign antigens. Thymic involution begins during puberty and progresses at a rate of about $3 \%$ per year until middle age, whereupon the rate of atrophy decreases to about $1 \%$ per year. ${ }^{36}$ This process leads to a reduction in thymic output of naive T lymphocytes, ${ }^{37}$ down-regulation of TCR gene rearrangement, ${ }^{38}$ and a greater reliance on peripheral memory cells and terminally differentiated effector $\mathrm{T}$ cells ${ }^{39}$ As a consequence, the range of TCR diversity becomes progressively more limited with aging.

Thymic output also is important for immune reconstitution after cytoreductive therapy. This has been shown in several studies examining the rate of T-lymphocyte repopulation after myeloablative chemotherapy. ${ }^{40,41}$ TCR rearrangement excision circles are episomal DNA circles generated during arrangement of TCR genes and are a useful marker of thymic output. 42,43 In a study of 40 adults aged 34 to 66 years who received myeloablative chemotherapy followed by autologous stem cell transplantation for multiple myeloma, there was a negative correlation between age and T-lymphocyte reconstitution as measured by numbers of TCR rearrangement excision circles at 6 months and 1 year after engraftment. ${ }^{41}$

Cellular immunity may be impaired during the aging process through the action of regulatory $T$ cells $\left(T_{\text {reg }}\right)$. $T_{\text {reg }}$ cells have been shown to suppress the activation, proliferation, and cytokine production of effector $\mathrm{T}$ cells $\mathrm{s}^{44,45}$ and their absence has been associated with the development of autoimmunity. ${ }^{46}$ Studies of healthy volunteers have reported that $T_{\text {reg }}$ cells accumulate with aging. ${ }^{47,48}$ Furthermore, elderly individuals with comorbid conditions have higher levels of peripheral blood $\mathrm{T}_{\text {reg }}$ cells than their healthy counterparts, ${ }^{48}$ suggesting that the action of $\mathrm{T}_{\text {reg }}$ cells may lead to an enhanced susceptibility to infectious illness in the nonhealthy elderly population. The role of $\mathrm{T}_{\text {reg }}$ cells in kidney transplantation remains unclear, with conflicting evidence regarding their impact on acute rejection. ${ }^{49-52}$ However, it is tempting to postulate that $T_{\text {reg }}$ cells participate in the increased vulnerability of the elderly transplant recipient to the effects of immunosuppression.

\section{Summary and Conclusions}

Changes in both innate and adaptive immunity occur with aging, which may help to explain an increased susceptibility to infectious illness and the decreased acute rejection observed in elderly transplant recipients. ${ }^{20}$

\section{Immunosuppression in the Elderly Transplant Recipient}

\section{Introduction}

Few studies have carefully evaluated the impact of different immunosuppressive drug protocols in the elderly. Many of the earlier prospective clinical trials did not include a significant number of elderly transplant recipients and much of the evidence concerning the effect of specific immunosuppressive agents arises from retrospective database studies or small observational series. Given the paucity of data, it is difficult to draw conclusions on the pharmacodynamic effects of specific immunosuppressive agents in the elderly.

\section{Pharmacokinetics}

Physiologic changes that occur in aging may alter drug pharmacokinetics. Bioavailability may be influenced by decreased intestinal or hepatic first-pass metabolism ${ }^{53}$ and the volume of distribution of lipophilic drugs, such as cyclosporine, may increase as the relative fat content increases with age ${ }^{54}$ Protein binding may decrease by up to $15 \%$ to $25 \%$ in elderly individuals 
compared with younger adults, which can lead to increased free plasma concentrations of immunosuppressive medications. ${ }^{55}$ This is particularly relevant in the case of mycophenolic acid, in which the free fraction represents the active inhibitory component to inosine monophosphate dehydrogenase. ${ }^{56}$ Hypoalbuminemia may result in increased exposure to mycophenolic acid, thereby enhancing the immunosuppressive effect of mycophenolic acid and increasing the risk for drug toxicity. ${ }^{56}$ Furthermore, aging is associated with reduced hepatic and renal clearance, which may be compounded by cofactors such as frailty, comorbidity, and polypharmacy. ${ }^{57}$

In a study of cyclosporine pharmacokinetics, elderly transplant recipients (defined as $>65 \mathrm{y}$ ) required significantly lower doses of cyclosporine to achieve similar target drug concentrations as young recipients. ${ }^{58}$ In addition, clearance of cyclosporine was lower and intracellular Tlymphocyte concentrations of cyclosporine, which have been shown to negatively correlate with rejection, ${ }^{59}$ were higher in elderly patients compared with younger patients. ${ }^{58}$ Although pharmacodynamic data are lacking, these findings suggest that the elderly may have an increased susceptibility to the immunosuppressive effects of cyclosporine.

\section{Immunosuppression and Infections}

There are conflicting data on the effect of mycophenolate mofetil (MMF) on infectious outcomes in elderly renal transplant recipients. A small, single-center, observational study reported that patients older than age 60 receiving a maintenance regimen of cyclosporine, MMF, and prednisone had an increase in overall infections, opportunistic infections (mainly cytomegalovirus and fungal infections), and hospitalizations compared with similarly aged recipients receiving cyclosporine, azathioprine, and prednisone. ${ }^{60}$ However, limitations of this study included a small sample size, differences in length of follow-up evaluation between each study group, different formulations of cyclosporine used (Sandimmune in the azathioprine arm, and Neoral in the MMF arm; both from Novartis Pharmaceuticals, Basel, Switzerland), and the inclusion of several tacrolimus-treated patients instead of cyclosporine in the MMF group. A later single-center retrospective study also suggested that MMF use was associated with a higher incidence of opportunistic infections (viral, fungal, and mycobacterial) and lower actuarial patient survival compared with azathioprine, but this study had similar limitations as the earlier-described study. ${ }^{61}$ In contrast, Sureshkumar and Nghiem ${ }^{62}$ reported greater patient and graft survival rates in MMF-treated elderly patients compared with azathioprine.

\section{Summary and Conclusions}

In light of the pharmacokinetic changes that may influence immunosuppression in the elderly, pharmacodynamic studies are needed to fully evaluate for differences in immunosuppressive potency that may exist in the older population. A variety of cofactors, including comorbidities, drug-drug interactions, diet, renal and hepatic function, and immunosenescence may influence the overall effect of immunosuppressive medications. These factors confound our ability to make generalizations about the effect of individual immunosuppressive drugs or drug protocols in the elderly and there is a need for refinement of immune monitoring assays to guide the choice and dosing of immunosuppression in older transplant recipients.

\section{Ethical Considerations in Organ Allocation}

\section{Introduction}

Given the persistent shortage of donor organs in the face of a steadily growing ESRD population, the earlier discussion highlights important ethical issues concerning allocation of scarce resources to the elderly. The evidence we have summarized leads one to conclude the following: (1) the survival benefit of transplantation over dialysis extends to the elderly population; (2) despite an increase in mortality, death-censored graft survival is comparable 
for elderly transplant recipients compared with their younger counterparts; and (3) there is survival benefit associated with ECD transplantation compared with dialysis, however, patient and graft outcomes are worse with ECD transplantation compared with living donor and SCD transplantation. Both the elderly and younger transplant candidates may enjoy similar relative benefits with transplantation; however, younger patients generally have a greater life expectancy. Several ethical questions should be considered in light of the available data. Should younger patients have priority in receiving a younger deceased donor kidney, as is currently the policy in the United States? (Kidneys from donors younger than age 35 are offered preferentially, with some exceptions, to pediatric candidates.) Should older kidneys be restricted to the elderly population? Can living donor transplantation be justified when there is a limited benefit of additional life-years? A major consideration in the development of an equitable organ allocation scheme is the balance of utility, in which kidneys are offered to those candidates who would derive the greatest benefit from transplantation, versus justice, in which all age groups have equal access to deceased donor kidneys.

\section{Organ Allocation}

The ESP experience has shown that preferentially allocating older kidneys to older recipients can reduce waiting time for transplantation. ${ }^{12}$ However, recipients older than age 65 who received older kidneys had lower patient and graft survival rates than recipients of younger deceased donor kidneys. ${ }^{12}$ It is not known to what extent shorter waiting time has impacted outcomes in the elderly ESRD population in the Eurotransplant region. It would seem that a better measure of the ESP's success would be a comparison of outcomes of patients transplanted under ESP with a similar age-matched cohort on the transplant waiting list. Although these data are not available from Eurotransplant, data from the United States do indicate that transplantation of an elderly recipient with an older (ECD) kidney offers a survival benefit over dialysis. $5,27,28$

In 2004, the OPTN/United Network for Organ Sharing Kidney Transplantation Committee sought to refine the deceased donor kidney allocation algorithm in an effort to create a more equitable allocation process. Their efforts culminated in a public forum held in Dallas, Texas, on February 8, 2007, that solicited recommendations on how to improve the current kidney allocation scheme. A major initiative arising out of the meeting was to develop an allocation scheme that would match anticipated survival of both the kidney allograft and the recipient by incorporating a measure of utility (estimate of life-years after transplant) and justice (time spent on dialysis) in relation to an estimate of donor quality (donor profile index). The committee currently is reviewing methods for estimating life-years after transplant, ${ }^{63}$ and current iterations of these models were discussed at a second public forum in St. Louis, Missouri, on January 26, 2009. More information about the concepts under consideration for kidney allocation can be found at www.optn/org/kars.asp.

\section{Quality of Life}

The impact of transplantation on quality of life should be considered in a discussion of organ allocation and the elderly. In general, transplant patients report an improved quality of life compared with dialysis patients in measures of health perception, physical and social functioning, and vitality. ${ }^{64-66}$ The nationally standardized SF-36 (36-item short form) is a quality-of-life questionnaire encompassing 8 scales: physical functioning, role limitation due to physical health problems, bodily pain, social functioning, mental health, role limitation due to emotional problems, overall vitality (energy and fatigue), and general health perception. ${ }^{67}$ Studies of older transplant recipients compared with similar-aged dialysis patients indicate that transplantation is associated with higher SF-36 scores. ${ }^{68,69}$ Among the predictors of improved health-related quality of life in the elderly transplant recipient are a lower rate of pretransplantation and posttransplant hospitalizations and fewer side effects of 
immunosuppression ${ }^{70}$ reinforcing that a complicated posttransplant course may have a detrimental effect on perceived health status. Therefore, although elderly transplant candidates generally can anticipate an improved quality of life with transplantation over dialysis, identification of risk factors for posttransplant complications is paramount. Factors impacting transplant outcome that are prevalent in the elderly population include malnutrition, depression, poor functional status, and social isolation. ${ }^{71-74}$

\section{Summary and Conclusions}

The decision to proceed with transplantation in the elderly candidate requires careful consideration of the individual-level risks weighted against the expected gains in life duration and quality.

\section{Conclusions}

In general, elderly ESRD patients benefit from kidney transplantation by gaining an increase in life expectancy and improved quality of life over dialysis. However, donor organs are a limited resource and equitable allocation of kidney transplants requires a balance between utility and justice. Similar to younger recipients, donor quality strongly impacts patient and transplant outcomes in the elderly, but allocation of older kidneys to older recipients may improve survival by decreasing transplant waiting time. It is important to recognize that risk factors such as malnutrition, depression, poor functional status, and social isolation may predict a complicated posttransplant course. As of yet, the upper age limit for transplantation has not been defined, although it seems that physiologic age, rather than chronologic age, would likely be a better predictor of posttransplant outcome. Advanced chronologic age, in and of itself, should not preclude a patient from kidney transplant because the available evidence suggests favorable transplant outcomes in the elderly. Therefore, after carefully weighing the risks and benefits of transplantation, elderly ESRD patients should continue to be considered for kidney transplantation, with case-by-case individualization rather than generalizations about therapeutic options based on age alone.

\section{References}

1. Wolfe RA, Ashby VB, Milford EL, Ojo AO, Ettenger RE, Agodoa LY, et al. Comparison of mortality in all patients on dialysis, patients on dialysis awaiting transplantation, and recipients of a first cadaveric transplant. N Engl J Med 1999;341:1725-30. [PubMed: 10580071]

2. US Renal Data System. USRDS 2008 annual data report: atlas of end-stage renal disease in the United States. Bethesda, MD: National Institutes of Health, National Institute of Diabetes and Digestive and Kidney Diseases; 2008.

3. Segev DL, Kucirka LM, Oberai PC, Parekh RS, Boulware LE, Powe NR, et al. Age and comorbidities are effect modifiers of gender disparities in renal transplantation. J Am Soc Nephrol. 2009

4. Humar A, Denny R, Matas AJ, Najarian JS. Graft and quality of life outcomes in older recipients of a kidney transplant. Exp Clin Transplant 2003;1:69-72. [PubMed: 15859911]

5. Rao PS, Merion RM, Ashby VB, Port FK, Wolfe RA, Kayler LK. Renal transplantation in elderly patients older than 70 years of age: results from the Scientific Registry of Transplant Recipients. Transplantation 2007;83:1069-74. [PubMed: 17452897]

6. Port FK, Bragg-Gresham JL, Metzger RA, Dykstra DM, Gillespie BW, Young EW, et al. Donor characteristics associated with reduced graft survival: an approach to expanding the pool of kidney donors. Transplantation 2002;74:1281-6. [PubMed: 12451266]

7. Oniscu GC, Brown H, Forsythe JL. How great is the survival advantage of transplantation over dialysis in elderly patients? Nephrol Dial Transplant 2004;19:945-51. [PubMed: 15031354]

8. Johnson DW, Herzig K, Purdie D, Brown AM, Rigby RJ, Nicol DL, et al. A comparison of the effects of dialysis and renal transplantation on the survival of older uremic patients. Transplantation 2000;69:794-9. [PubMed: 10755528] 
9. Shah T, Bunnapradist S, Hutchinson I, Pravica V, Cho YW, Mendez R, et al. The evolving notion of "senior" kidney transplant recipients. Clin Transplant 2008;22:794-802. [PubMed: 18713264]

10. Otero-Ravina F, Rodriguez-Martinez M, Gude F, Gonzalez-Juanatey JR, Valdes F, Sanchez-Guisande D. Renal transplantation in the elderly: does patient age determine the results? Ageing 2005;34:5837.

11. Nunes P, Mota A, Parada B, Figueiredo A, Rolo F, Bastos C, et al. Do elderly patients deserve a kidney graft? Transplant Proc 2005;37:2737-42. [PubMed: 16182796]

12. Frei U, Noeldeke J, Machold-Fabrizii V, Arbogast H, Margreiter R, Fricke L, et al. Prospective agematching in elderly kidney transplant recipients—a 5-year analysis of the Eurotransplant Senior Program. Am J Transplant 2008;8:50-7. [PubMed: 17973969]

13. Fabrizii V, Winkelmayer WC, Klauser R, Kletzmayr J, Saemann MD, Steininger R, et al. Patient and graft survival in older kidney transplant recipients: does age matter? J Am Soc Nephrol 2004;15:1052-60. [PubMed: 15034109]

14. Oniscu GC, Brown H, Forsythe JL. How old is old for transplantation? Am J Transplant 2004;4:206774. [PubMed: 15575911]

15. Meier-Kriesche HU, Ojo AO, Cibrik DM, Hanson JA, Leichtman AB, Magee JC, et al. Relationship of recipient age and development of chronic allograft failure. Transplantation 2000;70:306-10. [PubMed: 10933154]

16. Keith DS, Cantarovich M, Paraskevas S, Tchervenkov J. Recipient age and risk of chronic allograft nephropathy in primary deceased donor kidney transplant. Transpl Int 2006;19:649-56. [PubMed: 16827682]

17. Wu C, Shapiro R, Tan H, Basu A, Smetanka C, Morgan C, et al. Kidney transplantation in elderly people: the influence of recipient comorbidity and living kidney donors. J Am Geriatr Soc 2008;56:231-8. [PubMed: 18070005]

18. Mendonca HM, Dos Reis MA, de Castro de Cintra Sesso R, Camara NO, Pacheco-Silva A. Renal transplantation outcomes: a comparative analysis between elderly and younger recipients. Clin Transplant 2007;21:755-60. [PubMed: 17988270]

19. Heldal K, Leivestad T, Hartmann A, Svendsen MV, Lien BH, Midtvedt K. Kidney transplantation in the elderly-the Norwegian experience. Nephrol Dial Transplant 2008;23:1026-31. [PubMed: 18079146]

20. Meier-Kriesche HU, Ojo A, Hanson J, Cibrik D, Lake K, Agodoa LY, et al. Increased immunosuppressive vulnerability in elderly renal transplant recipients. Transplantation 2000;69:885-9. [PubMed: 10755545]

21. Meier-Kriesche HU, Srinivas TR, Kaplan B. Interaction between acute rejection and recipient age on long-term renal allograft survival. Transplant Proc 2001;33:3425-6. [PubMed: 11750467]

22. Gill J, Bunnapradist S, Danovitch GM, Gjertson D, Gill JS, Cecka M. Outcomes of kidney transplantation from older living donors to older recipients. Am J Kidney Dis 2008;52:541-52. [PubMed: 18653267]

23. Ojo AO, Hanson JA, Wolfe RA, Leichtman AB, Agodoa LY, Port FK. Long-term survival in renal transplant recipients with graft function. Kidney Int 2000;57:307-13. [PubMed: 10620213]

24. 2007 Annual Report of the US Organ Procurement and Transplantation Network and the Scientific Registry of Transplant Recipients: transplant data 1997-2006. Rockville, MD: Health Resources and Services Administration, Healthcare Systems Bureau, Division of Transplantation;

25. Meier-Kriesche HU, Kaplan B. Waiting time on dialysis as the strongest modifiable risk factor for renal transplant outcomes: a paired donor kidney analysis. Transplantation 2002;74:1377-81. [PubMed: 12451234]

26. Gill JS, Tonelli M, Johnson N, Kiberd B, Landsberg D, Pereira BJ. The impact of waiting time and comorbid conditions on the survival benefit of kidney transplantation. Kidney Int 2005;68:2345-51. [PubMed: 16221239]

27. Merion RM, Ashby VB, Wolfe RA, Distant DA, Hulbert-Shearon TE, Metzger RA, et al. Deceaseddonor characteristics and the survival benefit of kidney transplantation. JAMA 2005;294:2726-33. [PubMed: 16333008] 
28. Schold JD, Meier-Kriesche HU. Which renal transplant candidates should accept marginal kidneys in exchange for a shorter waiting time on dialysis? Clin J Am Soc Nephrol 2006;1:532-8. [PubMed: $17699256]$

29. Kauffman HM, McBride MA, Cors CS, Roza AM, Wynn JJ. Early mortality rates in older kidney recipients with comorbid risk factors. Transplantation 2007;83:404-10. [PubMed: 17318072]

30. Go AS, Chertow GM, Fan D, McCulloch CE, Hsu CY. Chronic kidney disease and the risks of death, cardiovascular events, and hospitalization. N Engl J Med 2004;351:1296-305. [PubMed: 15385656]

31. Meier-Kriesche HU, Ojo AO, Hanson JA, Kaplan B. Exponentially increased risk of infectious death in older renal transplant recipients. Kidney Int 2001;59:1539-43. [PubMed: 11260418]

32. Sieburg HB, Cho RH, Dykstra B, Uchida N, Eaves CJ, Muller-Sieburg CE. The hematopoietic stem compartment consists of a limited number of discrete stem cell subsets. Blood 2006;107:2311-6. [PubMed: 16291588]

33. Muller-Sieburg C, Sieburg HB. Stem cell aging: survival of the laziest? Cell Cycle 2008;7

34. Muller-Sieburg CE, Cho RH, Karlsson L, Huang JF, Sieburg HB. Myeloid-biased hematopoietic stem cells have extensive self-renewal capacity but generate diminished lymphoid progeny with impaired IL-7 responsiveness. Blood 2004;103:4111-8. [PubMed: 14976059]

35. Cho RH, Sieburg HB, Muller-Sieburg CE. A new mechanism for the aging of hematopoietic stem cells: aging changes the clonal composition of the stem cell compartment but not individual stem cells. Blood 2008;111:5553-61. [PubMed: 18413859]

36. Bradley BA. Rejection and recipient age. Transpl Immunol 2002;10:125-32. [PubMed: 12216942]

37. Pido-Lopez J, Imami N, Aspinall R. Both age and gender affect thymic output: more recent thymic migrants in females than males as they age. Clin Exp Immunol 2001;125:409-13. [PubMed: $11531948]$

38. Ortman CL, Dittmar KA, Witte PL, Le PT. Molecular characterization of the mouse involuted thymus: aberrations in expression of transcription regulators in thymocyte and epithelial compartments. Int Immunol 2002;14:813-22. [PubMed: 12096041]

39. Hakim FT, Flomerfelt FA, Boyiadzis M, Gress RE. Aging, immunity and cancer. Curr Opin Immunol 2004;16:151-6. [PubMed: 15023406]

40. Mackall CL, Fleisher TA, Brown MR, Andrich MP, Chen CC, Feuerstein IM, et al. Age, thymopoiesis, and CD4+ T-lymphocyte regeneration after intensive chemotherapy. N Engl J Med 1995;332:1439. [PubMed: 7800006]

41. Douek DC, Vescio RA, Betts MR, Brenchley JM, Hill BJ, Zhang L, et al. Assessment of thymic output in adults after haematopoietic stem-cell transplantation and prediction of T-cell reconstitution. Lancet 2000;355:1875-81. [PubMed: 10866444]

42. Dion ML, Sekaly RP, Cheynier R. Estimating thymic function through quantification of T-cell receptor excision circles. Methods Mol Biol 2007;380:197-213. [PubMed: 17876095]

43. Sodora DL, Douek DC, Silvestri G, Montgomery L, Rosenzweig M, Igarashi T, et al. Quantification of thymic function by measuring $\mathrm{T}$ cell receptor excision circles within peripheral blood and lymphoid tissues in monkeys. Eur J Immunol 2000;30:1145-53. [PubMed: 10760804]

44. Dieckmann D, Plottner H, Berchtold S, Berger T, Schuler G. Ex vivo isolation and characterization of CD4(+)CD25(+) T cells with regulatory properties from human blood. J Exp Med 2001;193:130310. [PubMed: 11390437]

45. Thornton AM, Shevach EM. CD4+CD25+ immunoregulatory T cells suppress polyclonal T cell activation in vitro by inhibiting interleukin 2 production. J Exp Med 1998;188:287-96. [PubMed: 9670041]

46. Sakaguchi S, Sakaguchi N, Asano M, Itoh M, Toda M. Immunologic self-tolerance maintained by activated T cells expressing IL-2 receptor alpha-chains (CD25). Breakdown of a single mechanism of self-tolerance causes various autoimmune diseases. J Immunol 1995;155:1151-64. [PubMed: 7636184]

47. Gregg R, Smith CM, Clark FJ, Dunnion D, Khan N, Chakraverty R, et al. The number of human peripheral blood CD4+ CD25high regulatory T cells increases with age. Clin Exp Immunol 2005;140:540-6. [PubMed: 15932517] 
48. Trzonkowski P, Szmit E, Mysliwska J, Mysliwski A. CD4+CD25+ T regulatory cells inhibit cytotoxic activity of CTL and NK cells in humans-impact of immunosenescence. Clin Immunol 2006;119:30716. [PubMed: 16545982]

49. Louis S, Braudeau C, Giral M, Dupont A, Moizant F, Robillard N, et al. Contrasting CD25hiCD4+T cells/FOXP3 patterns in chronic rejection and operational drug-free tolerance. Transplantation 2006;81:398-407. [PubMed: 16477227]

50. Braudeau C, Racape M, Giral M, Louis S, Moreau A, Berthelot L, et al. Variation in numbers of CD4 +CD25highFOXP3+ T cells with normal immuno-regulatory properties in long-term graft outcome. Transpl Int 2007;20:845-55. [PubMed: 17854443]

51. Bestard O, Cruzado JM, Rama I, Torras J, Goma M, Seron D, et al. Presence of FoxP3+ regulatory T cells predicts outcome of subclinical rejection of renal allografts. J Am Soc Nephrol 2008;19:2020_ 6. [PubMed: 18495961]

52. Veronese F, Rotman S, Smith RN, Pelle TD, Farrell ML, Kawai T, et al. Pathological and clinical correlates of FOXP3+ cells in renal allografts during acute rejection. Am J Transplant 2007;7:91422. [PubMed: 17286616]

53. Turnheim K. Drug dosage in the elderly. Is it rational? Drugs Aging 1998;13:357-79. [PubMed: 9829164]

54. Danovitch GM, Gill J, Bunnapradist S. Immunosuppression of the elderly kidney transplant recipient. Transplantation 2007;84:285-91. [PubMed: 17700150]

55. Schmucker DL. Liver function and phase I drug metabolism in the elderly: a paradox. Drugs Aging 2001;18:837-51. [PubMed: 11772124]

56. Nowak I, Shaw LM. Mycophenolic acid binding to human serum albumin: characterization and relation to pharmacodynamics. Clin Chem 1995;41:1011-7. [PubMed: 7600680]

57. Kinirons MT, O'Mahony MS. Drug metabolism and ageing. Br J Clin Pharmacol 2004;57:540-4. [PubMed: 15089805]

58. Falck P, Asberg A, Byberg KT, Bremer S, Bergan S, Reubsaet JL, et al. Reduced elimination of cyclosporine A in elderly (>65 years) kidney transplant recipients. Transplantation 2008;86:1379_ 83. [PubMed: 19034006]

59. Falck P, Asberg A, Guldseth H, Bremer S, Akhlaghi F, Reubsaet JL, et al. Declining intracellular Tlymphocyte concentration of cyclosporine a precedes acute rejection in kidney transplant recipients. Transplantation 2008;85:179-84. [PubMed: 18212621]

60. Meier-Kriesche HU, Friedman G, Jacobs M, Mulgaonkar S, Vaghela M, Kaplan B. Infectious complications in geriatric renal transplant patients: comparison of two immunosuppressive protocols. Transplantation 1999;68:1496-502. [PubMed: 10589946]

61. Johnson DW, Nicol DL, Purdie DM, Preston JM, Brown AM, Hawley CM, et al. Is mycophenolate mofetil less safe than azathioprine in elderly renal transplant recipients? Transplantation 2002;73:1158-63. [PubMed: 11965051]

62. Sureshkumar KK, Nghiem DD. Use of mycophenolate mofetil in immunosuppressive protocols in elderly renal transplant recipients. Transplantation 2003;76:441-2. [PubMed: 12883215]

63. Wolfe RA, McCullough KP, Schaubel DE, Kalbfleisch JD, Murray S, Stegall MD, et al. Calculating life years from transplant (LYFT): methods for kidney and kidney-pancreas candidates. Am J Transplant 2008;8:997-1011. [PubMed: 18336702]

64. Fujisawa M, Ichikawa Y, Yoshiya K, Isotani S, Higuchi A, Nagano S, et al. Assessment of healthrelated quality of life in renal transplant and hemodialysis patients using the SF-36 health survey. Urology 2000;56:201-6. [PubMed: 10925078]

65. Ogutmen B, Yildirim A, Sever MS, Bozfakioglu S, Ataman R, Erek E, et al. Health-related quality of life after kidney transplantation in comparison intermittent hemodialysis, peritoneal dialysis, and normal controls. Transplant Proc 2006;38:419-21. [PubMed: 16549136]

66. Khan IH, Garratt AM, Kumar A, Cody DJ, Catto GR, Edward N, et al. Patients' perception of health on renal replacement therapy: evaluation using a new instrument. Nephrol Dial Transplant 1995;10:684-9. [PubMed: 7566583]

67. Ware JE Jr, Sherbourne CD. The MOS 36-item short-form health survey (SF-36). I. Conceptual framework and item selection. Med Care 1992;30:473-83. [PubMed: 1593914] 
68. Apostolou T, Hutchison AJ, Boulton AJ, Chak W, Vileikyte L, Uttley L, et al. Quality of life in CAPD, transplant, and chronic renal failure patients with diabetes. Ren Fail 2007;29:189-97. [PubMed: 17365935]

69. Rebollo P, Ortega F, Baltar JM, Badia X, Alvarez-Ude F, Diaz-Corte C, et al. Health related quality of life (HRQOL) of kidney transplanted patients: variables that influence it. Clin Transplant 2000;14:199-207. [PubMed: 10831077]

70. Rosenberger J, van Dijk JP, Nagyova I, Zezula I, Geckova AM, Roland R, et al. Predictors of perceived health status in patients after kidney transplantation. Transplantation 2006;81:1306-10. [PubMed: 16699459]

71. Dobbels F, Skeans MA, Snyder JJ, Tuomari AV, Maclean JR, Kasiske BL. Depressive disorder in renal transplantation: an analysis of Medicare claims. Am J Kidney Dis 2008;51:819-28. [PubMed: 18436093]

72. Guijarro C, Massy ZA, Wiederkehr MR, Ma JZ, Kasiske BL. Serum albumin and mortality after renal transplantation. Am J Kidney Dis 1996;27:117-23. [PubMed: 8546125]

73. Habwe VQ. Posttransplantation quality of life: more than graft function. Am J Kidney Dis 2006;47 (Suppl 2):S98-110. [PubMed: 16567244]

74. Kutner NG, Zhang R, Bowles T, Painter P. Pretransplant physical functioning and kidney patients' risk for posttransplantation hospitalization/death: evidence from a national cohort. Clin J Am Soc Nephrol 2006;1:837-43. [PubMed: 17699295]

75. Lansdorp PM, Dragowska W, Thomas TE, Little MT, Mayani H. Age-related decline in proliferative potential of purified stem cell candidates. Blood Cells 1994;20:376-81. [PubMed: 7538342]

76. Sharp A, Kukulansky T, Globerson A. In vitro analysis of age-related changes in the developmental potential of bone marrow thymocyte progenitors. Eur J Immunol 1990;20:2541-6. [PubMed: 1980109]

77. Stephan RP, Reilly CR, Witte PL. Impaired ability of bone marrow stromal cells to support Blymphopoiesis with age. Blood 1998;91:75-88. [PubMed: 9414271]

78. Stephan RP, Lill-Elghanian DA, Witte PL. Development of B cells in aged mice: decline in the ability of pro-B cells to respond to IL-7 but not to other growth factors. J Immunol 1997;158:1598-609. [PubMed: 9029095]

79. Haynes BF, Markert ML, Sempowski GD, Patel DD, Hale LP. The role of the thymus in immune reconstitution in aging, bone marrow transplantation, and HIV-1 infection. Annu Rev Immunol 2000;18:529-60. [PubMed: 10837068]

80. Naylor K, Li G, Vallejo AN, Lee WW, Koetz K, Bryl E, et al. The influence of age on T cell generation and TCR diversity. J Immunol 2005;174:7446-52. [PubMed: 15905594]

81. Shodell M, Siegal FP. Circulating, interferon-producing plasmacytoid dendritic cells decline during human ageing. Scand J Immunol 2002;56:518-21. [PubMed: 12410802]

82. Castle SC, Uyemura K, Crawford W, Wong W, Klaustermeyer WB, Makinodan T. Age-related impaired proliferation of peripheral blood mononuclear cells is associated with an increase in both IL-10 and IL-12. Exp Gerontol 1999;34:243-52. [PubMed: 10363790]

83. Yen CJ, Lin SL, Huang KT, Lin RH. Age-associated changes in interferon-gamma and interleukin-4 secretion by purified human CD4+ and CD8+ T cells. J Biomed Sci 2000;7:317-21. [PubMed: 10895055]

84. Ershler WB, Keller ET. Age-associated increased interleukin-6 gene expression, late-life diseases, and frailty. Annu Rev Med 2000;51:245-70. [PubMed: 10774463]

85. Whisler RL, Beiqing L, Chen M. Age-related decreases in IL-2 production by human T cells are associated with impaired activation of nuclear transcriptional factors AP-1 and NF-AT. Cell Immunol 1996;169:185-95. [PubMed: 8620546]

86. Lages CS, Suffia I, Velilla PA, Huang B, Warshaw G, Hildeman DA, et al. Functional regulatory T cells accumulate in aged hosts and promote chronic infectious disease reactivation. J Immunol 2008;181:1835-48. [PubMed: 18641321]

87. Rukavina D, Laskarin G, Rubesa G, Strbo N, Bedenicki I, Manestar D, et al. Age-related decline of perforin expression in human cytotoxic T lymphocytes and natural killer cells. Blood 1998;92:241020. [PubMed: 9746781] 


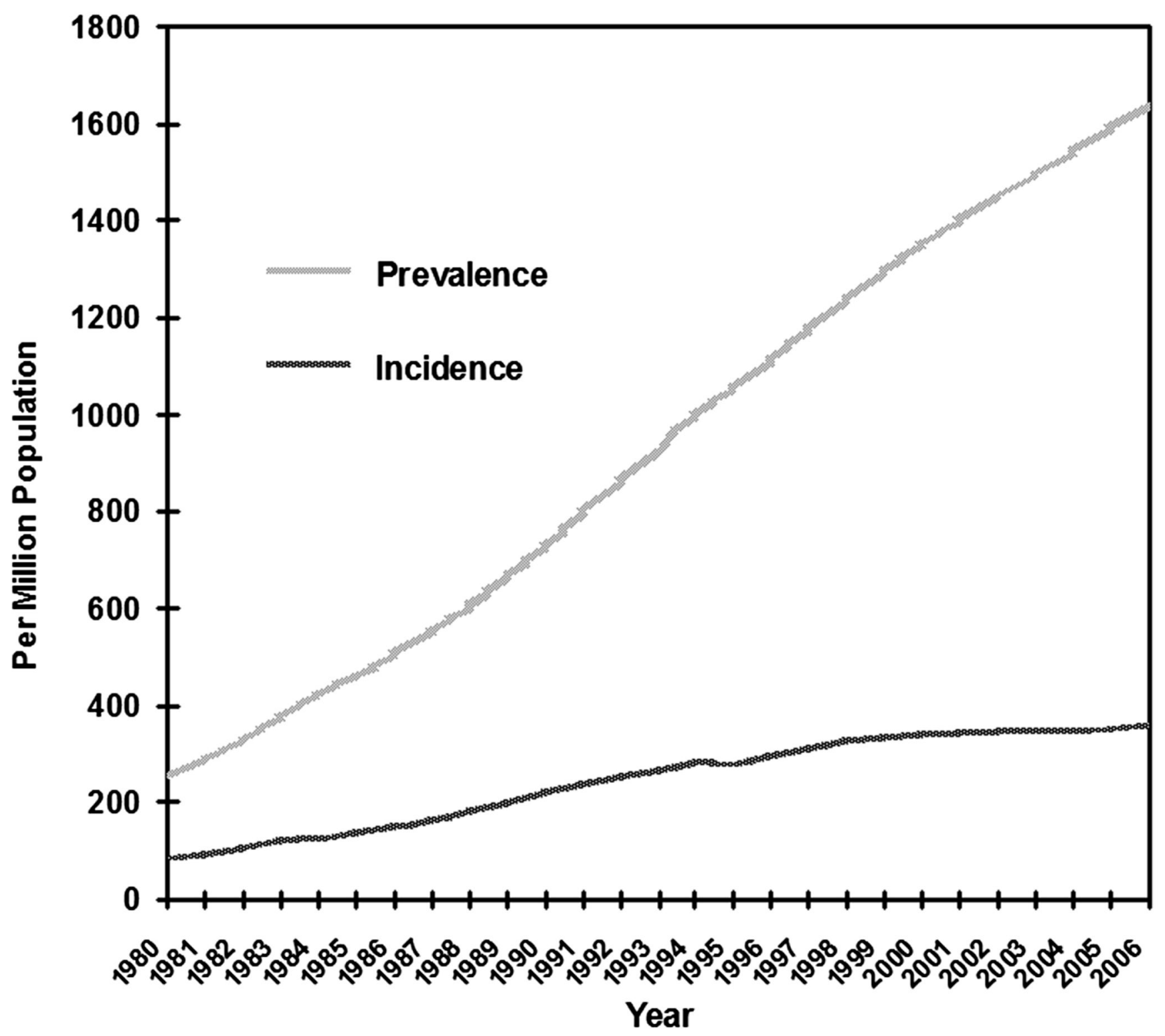

Figure 1.

Incidence and prevalence rates of ESRD in the United States from 1980 to 2006. Adapted from the US Renal Data System, USRDS 2008 Annual Data Report: Atlas of Chronic Kidney Disease and End-Stage Renal Disease in the United States, National Institutes of Health, National Institute of Diabetes and Digestive and Kidney Diseases, Bethesda, MD, 2008. The data reported here have been supplied by the USRDS. The interpretation and reporting of these data are the responsibility of the author(s) and in no way should be seen as an official policy or interpretation of the US government. 


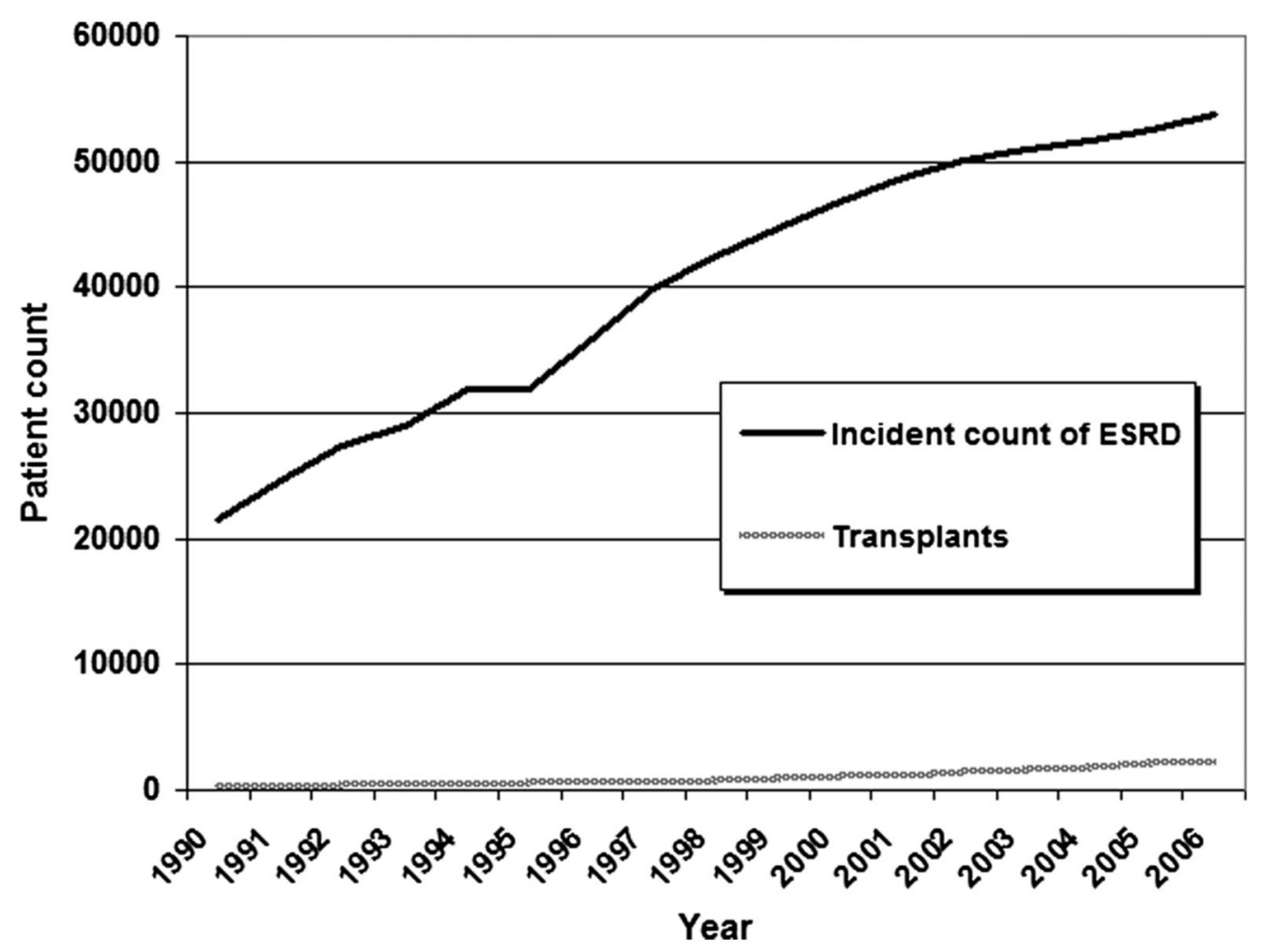

Figure 2.

Incident ESRD and kidney transplant counts in patients older than age 65 from 1990 to 2006 in the United States. Adapted from the US Renal Data System, USRDS 2008 Annual Data Report: Atlas of Chronic Kidney Disease and End-Stage Renal Disease in the United States, National Institutes of Health, National Institute of Diabetes and Digestive and Kidney Diseases, Bethesda, MD, 2008. The data reported here have been supplied by the USRDS. The interpretation and reporting of these data are the responsibility of the author(s) and in no way should be seen as an official policy or interpretation of the US government. 

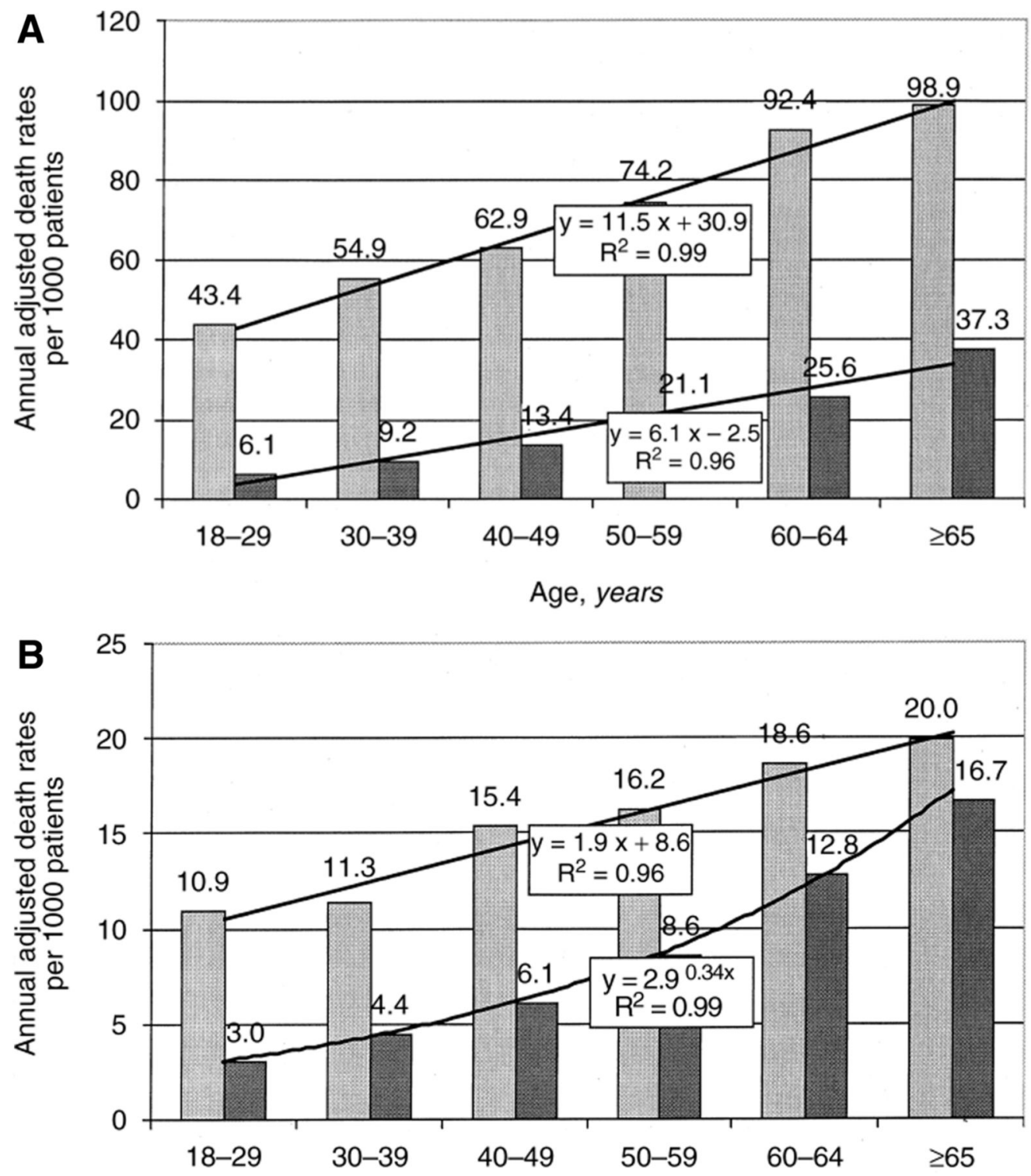

Age, years

Figure 3.

The association of age on (A) cardiovascular and (B) infection-related mortality in wait-listed (gray bars) and transplant patients (black bars). Reprinted with permission from MeierKriesche et al. ${ }^{31}$ 


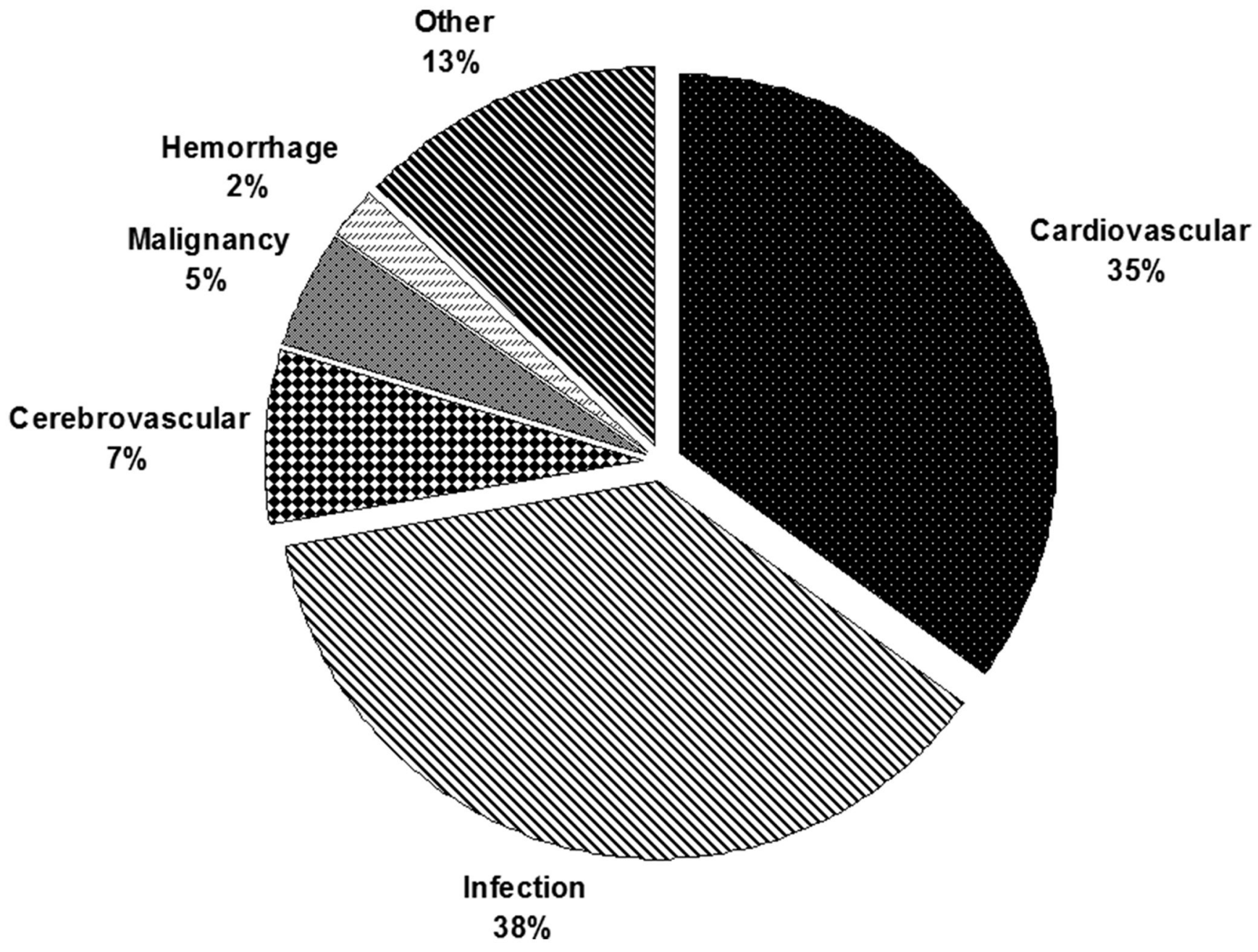

Figure 4.

Causes of first-year mortality among renal transplant recipients older than age 60 in the United States. Adapted from Kauffman et al. ${ }^{29}$ 


\section{Table 1}

Changes in Immunity in the Elderly

\begin{tabular}{lll}
\hline Observation & Effect & References \\
\hline Decreased stem cell production & Decreased hematopoiesis & 75 \\
$\begin{array}{l}\text { Accumulation of myeloid-biased hematopoietic } \\
\text { stem cells }\end{array}$ & Decreased lymphopoiesis & $33-35$ \\
$\begin{array}{l}\text { Attenuated development of thymocyte and B-cell } \\
\text { progenitors }\end{array}$ & Decreased lymphopoiesis & $76-78$ \\
Thymic involution & $\begin{array}{l}\text { Reduction in naive T cells, limited TCR } \\
\text { diversity }\end{array}$ & $40,41,79,80$ \\
& $\begin{array}{l}\text { Delayed immune reconstitution after } \\
\text { cytoreductive therapy }\end{array}$ & 81 \\
Reduction in peripheral dendritic cell population & $\begin{array}{l}\text { Impaired T-cell proliferation and cytokine } \\
\text { production }\end{array}$ & $82-8485$ \\
Altered cytokine profile & $\begin{array}{l}\text { Increased IFN- } \gamma, \text { IL-6, IL-10, IL-12 Decreased } \\
\text { IL-2 production }\end{array}$ & $87,48,86$ \\
Increase in FOXP3 T reg cells & $\begin{array}{l}\text { Decreased effector T-cell and natural killer cell } \\
\text { response }\end{array}$ & 47 \\
Decreased perforin expression & Deficient cytolytic activity & 87 \\
\hline
\end{tabular}

Abbreviations: IFN, interferon; IL, interleukin. 